\title{
Constructive Aspects of Biosemiotics
}

\author{
Tommi Vehkavaara $^{1} \cdot$ Alexei Sharov $^{2}$
}

Published online: 13 August 2017

(C) Springer Science+Business Media B.V. 2017

Biosemiotics has emerged from the synthesis of biology and semiotics (Anderson et al. 1984), however its relations with other scientific, philosophical, and epistemological concepts are still not fully crystallized. This Special Issue is focused on constructive aspects of biosemiotics, more specifically on such a naturalized approach to agency, normativity, knowledge, and meaning that emphasizes the primacy of activity and real construction of the cognitive agents themselves as opposed to the view of agents as mainly passively or mechanically reacting. Such point of view has been central in many forms of constructivism which assumes that knowledge is actively constructed by humans or other cognitive agents (Piaget 1967). Several researchers have explored the relations between biosemiotics with constructivism (Bielecka 2012; Brier 2008; Huber and Schmidt-Tannwald 2008; Favareau 2010). The topics of interest related to construction could thus be in questions how do organisms and other agents construct: (a) themselves (self-construction) and (b) their local environment they are interacting with. The self-construction includes specifically the construction of the "knowledge", "world view", or Umwelt (of this constructing "self"), which is the result of the cognitive interaction of the organism/agent with its environment. The environment, in turn, contains typically other agents and their constructions, which implies that communication networks between organisms/agents are both constructed and have constructive power over their agents as well. Such constructive perspective is present in the works of theoretical precursors of biosemiotics, especially by Jakob von Uexküll (the concepts of functional circle and Umwelt), and Gregory Bateson (cybernetics and information), but to some extent also by C.S. Peirce (e.g. the meaning of a sign as constructed by its interpreter). Our attempt is to facilitate the discussion of other constructive theories which are less often employed in biosemiotics. These include second order cybernetics (Von Foerster 2003), autopoietic approaches (Maturana and Varela 1980), general systems theory (von Bertalanffy 1950), evolutionary

Tommi Vehkavaara

tommi.vehkavaara@uta.fi

1 Faculty of Social Sciences, University of Tampere, Tampere, Finland

2 Genetics Laboratory, National Institute on Aging, Baltimore, MD, USA 
epistemology (Lorenz 1941, 1973 and Campbell 1974), interactivism (Bickhard 2017), Richard Lewontin's $(1982,1991)$ emphasis on construction over adaptationism, and Jean Piaget's (1967) constructive learning theory and epistemology. ${ }^{1}$

In biology, the most characteristically constructivist approaches are so called "second order cybernetics", coined by Heinz von Forester in 1974 (Von Foerster 2003) and "autopoiesis" (Maturana and Varela 1980). Both second order cybernetics and autopoiesis adhere to the principles of "radical constructivism" (von Glasersfeld 1984) which assumes that the main relation of knowledge to reality is an adaptation rather than iconic correspondence. In other words, agential knowledge fits to reality, in the Darwinean sense, but does not necessarily include any representational relation to it. Radical constructivism characterizes knowledge as an adaptation of a cognitive structure, as opposed to other adaptations that deal with body structures. It is opposed to "metaphysical realism" which assumes that the world is independent of how humans or other agents view it, and therefore denies any creative contribution of agents to their knowledge. Second order cybernetics study organisms together with their environment as self-constructed unities characterized by "operational closure" (Von Foerster 2003). In contrast to traditional science, the system under investigation includes observers and agents who can (re)construct themselves and other components of the system on internal demand. Feedback regulation of such systems evolves naturally in contrast to the first-order cybernetic systems where the feedback is configured externally (e.g., by an engineer). The idea of closure comes from mathematics, where certain states in a multidimensional vector space, called eigen-vectors, appear self-sustained after repeated applications of the same linear transformation that is interpreted as a model of world change through time. Although the rules of world change are not fully known, it is assumed in second order cybernetics that certain agential states (eigenforms) and dynamic patterns (eigenbehaviors) become stabilized in the long term due to their reinforcement by the self-production network. Eigenbehaviors depend on the state and dynamics of the outer world, and thus they represent the world to a certain extent. But they also depend on the internal self-production network of the agency; thus changes of internal relations may lead to novel emergent representations of the world. If these changes are heritable, they are subject to natural selection, which results in a "selected self-organization" (Rocha 1998). At a higher level of complexity, agents learn to switch between distinct dynamic attractors (eigenforms or eigenbehaviors) on demand,

\footnotetext{
${ }^{1}$ The origin of constructive approach to mind, perception, and cognition can be traced back to Immanuel Kant's theory of cognition (Kant 1781), where all representational content (about the existing world) has its origin in sense perceptions but is always structured by the a priori forms of sensibility (time and space) and categories of understanding (e.g. causality). As necessary conditions of all cognition, time, space, and categories cannot have their origin in senses and therefore the a priori truths about them do not represent the world but our capacities to get into cognitive contact with the world. Most forms of constructivism are descendants of this overall view but in a naturalized or relativized form. Jakob von Uexküll (1909, 1920) extended the Kantian scheme to animal cognition and behavior. Konrad Lorenz (1941) conjoined the views of Uexküll with Darwinian evolutionary theory by suggesting that Kantian cognitive structures may be a priori for an individual, but not for a species, i.e. that they are products of natural selection in phylogenetic evolution. This is the basic idea of evolutionary epistemology (Lorenz 1941; Lorenz 1973). Jean Piaget criticized Lorenz by emphasizing that such cognitive structures are constructed sequentially during the ontogenetic development, and thus, they are not ready at the birth of an individual (Piaget 1967). Piaget is often credited as the founder of constructive epistemology and learning theory.
} 
resulting in a new sign relation that links memory units with dynamic attractors in a context-dependent way (Rocha 1998).

We see the merit of radical constructivism in focusing on the pragmatic relation between knowledge and reality, which is indeed a fundamental feature of agency. This is especially important for understanding the living world of primitive organisms such as bacteria, which apparently have no capacity to access (e.g., categorize, track, and handle) the objects in the environment (Sharov and Vehkavaara 2015). Nevertheless, bacteria developed methods for coping with their environment without representing it at the object level. Their membrane receptors respond mostly to single features of the outer objects (objects from the human point of view, e.g., molecules or particles), which were "arbitrarily picked" by natural selection of bacteria as signals that are good enough to respond to and survive. However, radical constructivism appears unnecessarily restrictive in its agnostic approach to reality when applied to higher level organisms, such as humans and many animals. These organisms can categorize their highly multidimensional sensorial input and form relatively stable but updatable internal categories of objects. These categories function as a model that enable organisms to track and manipulate the objects of the world (Sharov 2017). The objects of the world are distinguished from the perspective of external observer and the internal object categories can be seen to correspond with some aspects of them in addition to being merely fit. Moreover, this match can be communicated between organisms to a certain extent due to its grounding in the intersubjective cognitive scaffolding (Hoffmeyer 2015). Communication of knowledge is not only enabled by scaffolding but also constrained by it, and in this respect, we agree with the criticism of metaphysical realism by radical constructivism.

The twentieth century biology has been dominated by the mechanistic methodology that has been applied to identify deterministic and stochastic effects of genetic and/or environmental factors on the phenotypic traits and behaviors of organisms. Biosemiotics, in turn, employs the semiotic view of life, which does not make such a priori assumption that the organic mechanisms that maintain stabilities and produce new ones (e.g., in evolutionary, developmental and behavioral "learning" processes) would be necessarily deterministic. Instead, the more complex the organisms are, the more degrees of freedom they may have. In this context, Jesper Hoffmeyer (2010) suggests that biosemiotic agents possess the varying degrees of semiotic freedom. For biosemiotics, it is typical to assume that the most important factors in organisms are sign relationships, the biological significance of which is not reducible to their physical appearance, because they are constructed by organisms (or by evolving lineages of organisms) on the basis of utility, resemblance, connection, or convention.

Independently on the chosen semiotic terminology (e.g., sign, representation, meaning, or information), constructive biosemiotics understands the referents of these terms as being constructed by biosemiotic agents or systems. Either these referents are materially constructed (composed) by an agent, or some already existing and cognitively available material items (objects, properties, behaviors, etc.) are identified and taken into service by the agent so that only their semiotic roles are constructed. In both cases, material items are merely vehicles of their semiotic functioning and they are picked up for use according to the actual needs of agents. The activity of agents is controlled by their subsystems that are goal-directed or embodying some normative functional criteria, which in some cases enable agents to judge and detect the success of 
their semiotic operations. Although the developmental or short-term time scale is more natural in constructive view, longer scales can be considered to capture the evolutionary dynamics (see Sharov 2017). Agential constructions (habits, niches) may have longterm effects in evolution (e.g. Baldwin effect); also lineages and populations of organisms can be seen as "evolutionary agents" in some weaker sense capable of learning (evolutionary epistemology, vertical biosemiosis).

Constructive aspects can be found in the theories of all three major classics and predecessors of contemporary biosemiotics, Charles S. Peirce (1849-1914), Jakob von Uexküll (1864-1944), and Gregory Bateson (1904-1980). The constructive view is essential especially in Uexküll's and Bateson's approaches. It can be also found in certain Peirce's conceptions concerning meaning construction (pragmaticism) and perception. All three of them tried to give formal descriptions of cognitive processes and meanings of organisms: Peirce logico-semiotic one, and Uexküll and Bateson system theoretic ones in terms of functional circle, cybernetic feedback, and information.

Jakob von Uexküll $(1909,1920)$ objectified or naturalized the Kantian view to cognition by extending its domain of application into animal cognition and behavior (see Stjernfelt 2007: 228). His concepts of Umwelt and functional circle (Funktionskreis) are especially valuable for establishing links between constructivism and biosemiotics. The Umwelt of an organism is its environment as it is perceivable to the organism - it is the internal species specific model of the environment significant for the animal species in case. Umwelt is thus constituted of perceivable objects (or object categories) that are recognized and associated with functional meanings such as "food", "nest", or "enemy". The idea is that animal action starts from the perception of an object and ends to functionally relevant response toward the object so that perception and action conjoin the relation of animal subject and its object into a functional circle (von Uexküll 1920).

Uexküll's constructive approach introduces an important methodological outlook. The idea is to pay attention to the cognitive accessibility of an animal, what features of its environment are cognizable to it from the "1st person view". A scientist can, from his external " 3 rd person view", recognize also other features in the environment of the animal that may have impacts on the life of the animal but not through its cognitive apparatus (senses etc.). A scientist will thus have a double access to the objects of an animal, a direct one through scientist's own Umwelt and the indirect one through scientist's study of the cognitive structures of the animal (species), i.e. of its Umwelt. This double access opens up a possibility to compare the signs, representations, meanings, etc. of the animals of different species that refer to the same object (fixed by the direct access of a scientist). For example, deers belong to the Umwelts of both wolfs and ticks, but what a tick perceives about a deer (mainly the odor of butyric acid and temperature) is only a minor part of the relevant perceptions of a wolf (besides odor, also a visual pattern of a deer and tracking of its movements are crucial for a successful hunt).

It is typical to constructivist approaches (especially to second order cybernetics and radical constructivism) to consider that human Umwelt also provides similarly limited and constrained access to the world as the Umwelts of the other animals do. However, because humans have certain cognitive capacities that other animals do not seem to have, human Umwelts are less limited by the structure of senses than the Umwelts of 
many (or most) animals. The human cultural plasticity and diversity, our ability to compose new abstract concepts and shape our metaphysical and scientific beliefs and theories, widen the Umwelt of a scientist far beyond the concrete ontology due to our sensibility, common sense, subjective interests, and cultural conventions. ${ }^{2}$ The theorydependence of our observations is not an obstacle but a precondition for a more objective perspective. This does not nevertheless guarantee the validity or progressive development of the theoretical layers of human Umwelt - more objective perspective does not prevent us to end up in false but convenient doctrines or to make mistakes. But the wide variety of alternative beliefs and practices may enable us to look for more valid or otherwise better solutions.

It is often claimed that the "1st person view" is a characteristic feature of Uexküllian biosemiotics (Brier 2008; Tønnesen 2011). However, a biosemiotician can not employ the "1st person view" of a tick, cat, or crow, because as a human being, he/she cannot feel and cognise as a tick, cat, or crow. This does not mean that we could not know anything about animal Umwelts or their "1st person view", of course we can, but this knowledge is derived mostly from our external observations of the behavior, physiology, and environment of these animals. The "1st person" or "subjective" view emphasized in biosemiotics appears in fact as a kind of "objectified subjective view", i.e. it is about subjectivity from the "3rd person" external perspective (cf. Vehkavaara 2002). Therefore, the opposition between the 1 st and the 3rd person views is different in biosemiotics than in human studies, where scientists can employ both 1st and 3rd person access to human mind. E.g. phenomenological psychology may provide such experiential knowledge about human mind that is not available from the 3rd person perspective. Moreover, through linguistic communication it is possible to compare the 1 st person experiences of different people and find commonly understandable abstract concepts that represent the features of those 1st person experiences. In the studies of other species (and human infants), linguistic communication and shared conceptual understanding between the observer and observed is (mostly) unavailable and the only possibility is this "objectified 1st person view", which is implicitly employed by von Uexküll (1920: ch. 5), C.S. Peirce in his mature semiotics, and Mark Bickhard in his interactivist approach (2017).

Another major constructivist influence to biosemiotics comes from Gregory Bateson. Perhaps Bateson's most widely referred and accepted idea in biosemiotics is his famous definition of information: "an elementary unit of information is a difference that makes a difference" (Bateson 1972: 459). Bateson associated it with perception, but in biosemiotics it is often applied to information transfer by triadic signs. If the $1 \mathrm{st}$ difference is thought to be a sign to the (agential) system for which the 2nd difference is made (the meaning of the 1 st one), such a conception of sign appears as non-representational, because the object that the sign would represent has no role in the definition, in contrast to Peirce's theory. Peter Harries-Jones (this issue) explicates more closely the nature, development, and sources of Bateson's biological constructivism, and shows how Bateson's approach differs from both Uexküll's and Peirce's ones in being more interactionistically or communicationally oriented.

\footnotetext{
${ }^{2}$ John Deely (2004: 22) have suggested that human Umwelt could be associated with the Lebenswelt (of Husserlian phenomenology). This is close to the view presented here, if we allow theoretical terms of a scientist playing central part in scientist's Lebenswelt whenever he/she is interacting with his object of study.
} 
Charles S. Peirce's thinking is not usually associated with constructivism, because of his strong scientific "three category" realism and representational concept of triadic sign. Peirce's sign represents its object, and its interpretation aims to reveal the true nature of the object to the interpreter. ${ }^{3}$ However, this requires the construction of the progressive chain of interpretants by the interpreter. Peirce's "maxim of pragmatism" has oftentimes inspired philosophers and scientists to derive concepts of meaning, in which the meaning of a sign does not exist in some ideal universe before it emerges as the result of the interpreter's concrete action, i.e. that meaning is constructed by the interpreter. ${ }^{4}$ Mariana Vitti Rodrigues and Claus Emmeche (this issue) present one such Peirce-inspired conception of meaning in their study on abduction, i.e. the construction of an explanatory (or anticipatory) hypothesis to some surprising observation or practical problem.

For Peirce, abduction was the type of logical inference, only through which novel thoughts can emerge, and as such it has a close connection to the (logical) concept of perception": "abductive inference shades into perceptual judgment without any sharp line of demarcation between them" (Peirce CP 5.181, 1903). Peirce's point of view in his derivation of his logical conception of perception is the 1st person perspective of the perceiver, and the result seems to come close to Bateson's conception of information and perception. Peirce's conception of perception contains two elements: percept and perceptial judgment. Unlike signs, percepts do not represent anything for the perceiver. Peirce does not use the concept of perceptual object or the object of perception. Percepts are singular and compulsive events for the perceiver, the clashes of "ego and non-ego" that just happen without any possibility of control by the perceiver. Percepts are thus not signs for the perceiver, but Peirce assumed them to be the source of all the material content that signs and other mental representations may contain (Peirce EP 2:220-223, 1903). They function as information in the Batesonian sense. As singular events, percepts would come and go, leaving no other traces but physical stress unless a perceptual judgment is constructed. Only through perceptual judgment, a perceptual process can be transformed to a sign process and the event of perception can influence further thoughts and its aspects can be remembered (Peirce CP 7.643, 1903). The object of a perceptual judgment (as a propositional sign) is the percept from which it was originated, not any "thing" in the world. The semiotic process may proceed from a perceptual judgment and the hypotheses about the relevant causes of perception (the ordinary idea of perceived object) may be abducted. This abducted

\footnotetext{
${ }^{3}$ Peirce's realism does not include a commitment to the "metaphysical realism" of the kind that assumes existing world having completely mind-independent object structure. How the world is divided into objects may depend on the capacities and interests of the cognizing mind - the identification of objects is minddependent but what is true about them is not.

${ }^{4}$ Depending on the version of Peirce's definition of his pragmatism (that he gave during 1878-1909), the meaning of a sign is defined either as a conception (i.e. a proposition) that anticipates the possible future effects (or bearings) of the object represented (Peirce EP 1:132, 1878 and EP 2:340, 1905) or as a "sum" of all those possible future effects (Peirce CP 5.9, 1907). Other variations of the pragmatistic conception of meaning can be found from the writings of other classical pragmatists and it is often also associated (or confused) with Ludwig Wittgenstein's (1953) later view of meaning as (actual) use.

${ }^{5}$ Peirce's interest in his writings on perception in 1903 was a logical one, although strictly speaking, percepts or even perceptual judgments cannot be the subjects of logical critique because of their compulsory nature (Peirce CP 7.198). But perception is a kind of limiting case of a logical process, and Peirce was interested on how perceptions are connected to sign processes and transfer material contents to signs. This view should not be confused with psychological (3rd person view) descriptions of perceptual processes.
} 
"object of perception" is nevertheless not the object of a sign in this process, but a "theory" or hypothesis that may be true or false and that is inferred (Peirce CP 7.198), i.e. it is a constructed interpretant of the perceptual judgment, which may become fixed in perceiver's habits of action in further semiosis. ${ }^{6}$

\section{Overview of Papers of the Special Issue}

The introductory section of Alexei Sharov's paper gives an overview of some of the above mentioned constructive approaches and their possible influences on biosemiotics. Sharov's main topic is to introduce and argue for the relevant concept of biosemiotic agency. It is common to limit the occurrence of proper agency to rather high levels of organization and demand rather strong properties and capacities of autonomy, self-maintenance, and self-organization. Usually individual organisms are seen as prototypes of biological agents. Sharov nevertheless argues that it is reasonable to adopt a less demanding concept of agency so that even some molecules could have agential capacities. Many of the subsystems of organisms (e.g. organs, some cell-types, and even genes) function rather autonomously, although they are not really selfmaintained but maintained and constructed by the other subsystems of the whole. Similarly, organisms themselves are typically de facto heavily dependent on each other, their mutual maintenance and manipulation relations are complex and such ecosystemic interactive community is a natural condition of life for most organisms. Sharov's main thesis is that biosemiotic agents are on the one hand composite communities of the subagents, and on the other hand, tend to function as active parts of bigger wholes with varying degree of integration in organization.

One of the major challenges of biosemiotics is the nature of goal-directedness and normative functionality, as semiotic concepts seems to require them when applied to living systems. The paper by Mark Bickhard provides on overview to his interactivist approach that addresses these questions of the nature of goals, functionality, and normativity - how they can be treated naturalistically without eliminating or reducing them. In particular, the interactivist model provides a non-representational theory of the structure of cognitive mechanisms, on which also ordinary "encodingist" representationality is based. Bickhard's perspective is the objectified or naturalized 1st person perspective - the goals, normativities, representations, functions, etc. must be available for or embodied in the suggested cognitive system.

It is characteristic to living systems that they are open interacting processes, the stability of which requires continuous maintenance. Because living systems are largely self-maintained, they must stay continuously active in their self-maintenance. This self-

\footnotetext{
${ }^{6}$ The mainstream view, where perceptions are thought to convey some information about the perceived objects of the world requires a 3rd person perspective to look at the perceptual processes, by comparing perceptions to the entities of the already achieved world view. Peirce does not deny the possibility of such a view: "Percepts are signs for psychology; but they are not so for phenomenology" (Peirce CP 8.300, 1904). However, the interpretants of such "percept-signs" are formed in the mind of this external observer and consequently, these perceptions are signs only to this observer. While humans can look at their own perceptions from both 1 st and 3rd person perspective, it is not clear if other species have a similar capacity. In particular the most simple organisms are not likely to have anything but the 1st person perspective (see e.g. Sharov and Vehkavaara 2015)
} 
influential activity provides the ultimate normative functionality - a system may fail in its self-maintenance. In Bickhard's model, such "die or live" -normativity of a selfmaintained system is the source of all phenomena of goal-directedness, representational errors, and normative functionality. In complex systems like organisms, this normativity does not concern only the whole system, but also its subsystems that have to do both: maintain themselves and participate in the maintenance of the whole. If some of these subsystems fail in serving either of their functions, other subsystems may detect such failures and launch some compensating maintenance processes, if the whole has already developed such error detecting and correctiong subsystem (Bickhard 2017). For instance, the state of metabolic starvation of unicellulars is often detected before it would lead to lethal inactivity, and this detection launches various alternative processes to correct the situation (e.g. by lowering energy consumption, movement to look for nutrition in other places, and/or producing specific enzymes to consume alternative nutrition resources).

Representationality occurs at various levels in Bickhard's scheme. At the most simple level, there are no objects to be represented, instead, representational processes are environmental interactions that result indications to action, which are successful if they manage to serve the function of self-maintenance in the current environment. ${ }^{7}$ Thus, at this primitive level, the representational error and failure in self-maintenance do coincide. More complex systems or organisms, may have developed specific sensors and other representational subsystems that form collectively an updatable situation image of the interactive possibilities. The temporal invariances in such a situation image can be called objects for the system if they are detected by the system. From the external perspective, we can then ask to which extent these "objects for the system" correspond to the objects recognized by us as external observers.

Krystyna Bielecka and Mira Marcinów employ some of the Bickhard's interactivist criteria of representationality to explain certain animal psychopathologies related to possible mental misrepresentations. Mental illnesses in animals are rather difficult to detect and identify, because normal methods of diagnosis by interviewing the patients are not available. Obsessive-compulsive disorders are often reliably diagnosed in some species of animals, but delusions are more difficult to detect although they may occur in some higher animals. In order to explain the dynamics of obsessive-compulsive disorders and delusions, Bielecka and Marcinow focus on mental misrepresentations by distinguishing interactive errors and representational errors. In particular, they combine Ruth Millikan's etiological concept of function with Bickhard's futureoriented dynamic conception of normative functionality. Relying on this combined conception, they provide an explanation how delusive misrepresentations in animals could be understood, even if an animal itself was not able to detect its misrepresentation.

Peter Harries-Jones provides an argumentative overview of the development of Gregory Bateson's constructive biological conceptions. Unlike Peirce and Uexküll, Bateson did not develop his approach from Kantian origins of individual mind. Bateson

\footnotetext{
7 The description of Bickhard's lowest level interactive representation comes structurally close to both Bateson's definition of information and Peirce's conception of the initial stage of perception. Peircean representational signs and sign processes, instead, would require much more complex cognitive systems (cf. Vehkavaara 2003).
} 
opposed the view that subjective consciousness is the starting point or decisive element in cognitive theory, instead, he described cognition as feedback loops in the network of information flows. Although Bateson was a pioneer of this "first order cybernetic view", his interest in the processes of learning and memory lead him to emphasize the circularity of these processes, which was a step towards second order cybernetics. When human observer describes non-living systems (pleroma) there is no cognitive feedback - observing living creatura is different, because reciprocal communication and recursive understanding of the creatural point of view is possible. Observer and observed live to some extent in the same world. Harries-Jones finds support to Batesonian biosemiotic approach in Ruth Millikan's biosemantics (Millikan 1989). Moving away from the language-centered analytic cognitive philosophy, Millikan introduces the concept of natural sign that is first formed in perception, and after that the sign itself becomes perceptible, which enables it to function as a sign of communication. Natural signs do not need to become conceptualized but their functioning is based on bodily behavioral anticipation, i.e. via recursive perceptual feedback loops, like in Bateson's approach.

At the birth of the modern science in the seventeenth century, a dispute concerning the origins of knowledge was acute. It was debated whether we have some innate ideas or do all our mental contents has sensorial origin. The revolutionary achievements of science in the nineteenth century created a common intuition that favors the empirist alternative: all our knowledge about the external world must have its origin in the sense experience. This intuition seems to be still influential even if the naive perceptual theory of classical empiricism were not accepted. For instance, all three theoretical precursors of biosemiotics (Peirce, Uexküll, and Bateson) seem to have accepted such thesis either implicitly or explicitly. Marcin Milkowski (this issue) considers the recent scenario of Fred Keijzer showing how non-empirical cognitive contents could emerge and how the nervous system might have been evolved. It appears that sensory input is not a necessary condition for the formation of neural system and minimal cognition, but instead, action-oriented feedback mechanisms are needed. This does not mean a denial of the importance of sensorial input in our cognitive contents, but it shows that our cognitive contents and structures may still include traces of elements that do not have perceptual origin, and instead are constructed in the developmental organismenvironment interaction that preceeds the development of sense organs or is not mediated by them.

Two papers of this special issue represent the autopoietic approach initiated by Humberto Maturana and Fransesco Varela in early 1970's (Maturana and Varela 1980). Steven Sergio Rubin follows in his paper Maturana's radically constructivist doctrine where the perspective of an autopoietic unity ("1st person") and the one of scientist or observer (3rd person) are strictly separated. Maturana was influenced by Uexküll's insistence on paying attention to organism's "1st person" perspective, from which he draw extreme requirements for both methodology and ontology: the descriptions of the system should rely only on this " 1 st person" perspective. Because the standard concepts or ideas of (genetic) information and code, self-organization, parts and wholes, etc. are considered to require the perspective of an observer, they are rejected from autopoetic theory. Rubin's specific topic is an "exogenomic" problem - if DNA cannot be said to contain information for the cell (following constructivism), how such phenomena as the functioning of viruses in cells and genetic engineering should be understood. Rubin 
keeps his focus at the cellular level employing Robert Rosen's notation “(M,R) system". ${ }^{8}$ He concludes that a cell as an autopoietic unity cannot make a difference between exogenomic and its own chromosomal DNA, as both participate equally in the autopoiesis of a cellular unity.

Jaime Cardenas-Garcia and Tim Ireland do not argue for strong ontological commitments but aim to provide a model, where organism-in-its-environment is taken as the basic unit of an autopoietic analysis. Although their model at its simplest level is applied to the dynamics of unicellular organisms, their goal in this paper is in explaining a much more complex human cognition. Authors develop a conception of distributed cognition that could be helpful in the analyses of emotions and social cognition, and would possibly explain how the interaction of autopoietic "organismsin-their-environment" can develop a "shared universe" that is cognitively available to all interacting agents.

The last two papers of this special issue deal with rather developed cognitive behaviors of certain higher animals. Filip Jaroš discusses the possibility of social cognition and genuine joint action and intentions in non-human animals. Jaroš challenges Michael Tomasello's arguments that genuine collaboration towards genuinely shared goal cannot be shown to occur even in such close relatives of humans as chimpanzees. Jaroš argues that this result that seems to be in conflict with many other studies of e.g. hunting practices of groups of animals is largely due to Tomasello's conceptual starting points in social philosophy and human psychology. Jaroš provides evidence that the social behavior of feral cats seems to include certain joint actions like communal maternal care of non-relative females. Some cats of the local group seem to form alliances that strongly resemble human friendship relations. Moreover, these alliances seem to be consolidated with some "symbolic meanings" that are given to some items (e.g. empty litter pan) in their local Umwelt, and that are jointly guarded and defended. Although this comes close to symbolization in human rituals studied in classical anthropology, such "symbols" seem to nevertheless lack their use for communicative or cognitive purposes, instead they seem to function as proper nouns, i.e. only as means for identification.

Mariana Vitti Rodrigues and Claus Emmeche, focuses on the questions what would be the usable concepts of information and abduction and their mutual relation so that they could be applied in problem solving in both human and non-human animals. More specifically, they consider the amazingly intelligent problem solving capacity of New-Caledonian crows as an example of behaviors that may include abductive inference. In this analysis they employ the semiotic conception of information that has been inspired by Peirce's writings and further developed by El-Hani et al. (2009). For Peirce, abduction was that type of inference, the function of which was mainly in the construction of explanatory hypotheses. Vitti Rodrigues and Emmeche follow Lorenzo Mangani's idea and distinguish the Peircean conception of explanatory abduction from the manipulative abduction that does not focus on "thinking in the head", but instead consider thinking through exploratory action.

\footnotetext{
${ }^{8}$ In Rosen's (M,R)-system, M refers to metabolism and $\mathrm{R}$ to repair, and the whole notation refers to the model of a cell where its activities are partitioned into two classes that reflect "the morphological partition between nucleus (genome) and cytoplasm (phenome), and the corresponding functional partition between what goes on in cytoplasm (the M of the system) and what goes on in nucleus (the R)" (Rosen 1998: 261).
} 
In summary, biosemiotics appears intrinsically related to constructive approaches in its sister disciplines, such as second order cybernetics, autopoiesis, constructivism, enactivism, and interactivism. This connection widens the scientific significance of biosemiotics as an integrating theoretical approach by providing a fruitful way to base semiotic concepts naturalistically but non-reductively. For biosemiotics, sign relations and meanings are components of reality, not just metaphors as it is often viewed in biology or cybernetics. Biosemiotics recognizes also the creative role of agency in knowledge construction, but avoids the agnostic attitude towards reality that is so common in radical constructivism. Biosemiotics assumes that semiotic scaffolds represented by heredity, phenotype, and behavior, both enable and limit (partially) the capacity of organisms to represent the reality in cognitive structures. Moreover, these scaffolds can be shared (partially) between communicating organisms, enabling meaningful transfer of knowledge. Thus, we see biosemiotics as a potential mediating field in the integration of semiotic and constructive approaches to agency and life.

\section{References}

Anderson, M., Deely, J., Krampen, M., Ransdell, J., Sebeok, T. A., \& von Uexküll, T. (1984). A semiotic perspective on the sciences: Steps toward a new paradigm. Semiotica, 52(1/2), 7-47.

Bateson, G. (1972). Steps to an ecology of mind. Chicago: University of Chicago Press.

Bickhard, M. H. (2017). Levels of representationality. Journal of Experimental \& Theoretical Artificial Intelligence, 10(2), 179-215 (this issue).

Bielecka, K. (2012). Biosemiotics and constructivism: Strong allies. Constructivist Foundations, 7(3), 228.

Brier, S. (2008). Cybersemiotics: Why information is not enough. Toronto: University of Toronto Press.

Campbell, D. T. (1988 [1974]). Evolutionary epistemology. In: D.T. Campbell: Methodology and epistemology for social sciences (pp. 393-434). (Ed. by E.S. Overmann) Chicago: University of Chicago Press.

Deely, J. (2004). Semiotics and Jakob von Uexküll's concept of umwelt. Sign Systems Studies, 32(1/2), 11-34.

El-Hani, C. N., Queiroz, J., \& Emmeche, C. (2009). Genes, information, and semiosis. (Tartu semiotics library, vol. 8). Tartu, Estonia: Tartu University Press.

Favareau, D. (2010). Introduction: An evolutionary history of biosemiotics. In D. Favreau (Ed.), Essential readings in biosemiotics: Anthology and commentary (pp. 1-77). Berlin: Springer.

Hoffmeyer, J. (2010). Semiotic freedom. An emerging frce. In P. Davies \& N. H. Gregersen (Eds.), Information and the nature of reality. From physics to metaphysics (pp. 185-204). Cambridge: Cambridge University Press.

Hoffmeyer, J. (2015). Introduction. Semiotic scaffolding. Biosemiotics, 8(2), 153-158.

Huber, J., \& Schmidt-Tannwald, I. (2008). A biosemiotic approach to epigenetics: Constructivist aspects. In M. Barbieri (Ed.), Introduction to biosemiotics (pp. 457-471). Berlin: Springer.

Kant, I. (1868 [1781]). Kritik der reinen Vernunft. (Critique of pure reason). Leipzig: Leopold Voss.

Lewontin, R. (1982). Organism and environment. In H. Plotkin (Ed.), Learning, development, and culture: essays in evolutionary epistemology (pp. 151-170). Chichester: John Wiley \& Sons.

Lewontin, R. (1991). Biology as ideology. New York: HarperCollins.

Lorenz, K. (1941). Kant's Lehre vom apriorischen im Lichte gegenwärtiger Biologie. Repr. In K. Lorenz \& F. Wuketits (Eds.), Die Evolution des Denkens (pp. 95-124). München, Zürich: Piper 1983.

Lorenz, K. (1973). Die Rückseite des Spiegels. Versuch einer Naturgeschichte menschlichen Erkennens. München: Deutscher Taschenbuch Verlag 1987.

Maturana, H., \& Varela, F. (1980). Autopoiesis and cognition: The realization of the living (Boston studies in the philosophy of science, vol. 42). Dordecht: D. Reidel Publishing Co.

Millikan, R. (1989). Biosemantics. Journal of Philosophy, 86(6), 281-297.

Peirce, C. S. (1931-1935, 1958). (CP) Collected Papers of C. S. Peirce. Vols. 1-6, ed. by C. Hartshorne, P. Weiss. Vols. 7-8, ed. by A.W. Burks. Cambridge: Harvard University Press.

Peirce, C.S. (1992, 1998). (EP) Essential Peirce. Selected Philosophical Writings. In N. Hauser et al. (Ed.), (vol. 1-2). Bloomington: Indiana University Press.

Piaget, J. 1967. Biology and Knowledge (orig. Biologie et connaissance). Edinburgh University Press 1971. 
Rocha, L. M. (1998). Selected self-organization and the semiotics of evolutionary systems. In: S. Salthe, G. Van de Vijver, \& M. Delpos (Eds.), Evolutionary systems: Biological and epistemological perspectives on selection and self-organization (pp. 341-358). Dordrecht: Springer.

Rosen, R. (1998). Essays on life itself. New York: Columbia University Press.

Sharov, A. A. (2017). Minimal mind. In: L. Swan (Ed.), Origins of mind (pp. 343-360). Dordrecht: Springer (this issue)

Sharov, A., \& Vehkavaara, T. (2015). Protosemiosis: Agency with reduced representation capacity. Biosemiotics, 8(1), 103-123.

Stjernfelt, F. (2007). Diagrammatology. Dordrecht: Springer.

Tønnesen, M. (2011). Umwelt transition and Uexküllian phenomenology. Tartu: Tartu University Press.

Vehkavaara, T. (2002). Why and how to naturalize semiotic concepts for biosemiotics. Sign Systems Studies, 30(1), 293-313.

Vehkavaara, T. (2003). Natural self-interest, interactive representation, and the emergence of objects and Umwelt. Sign Systems Studies, 31(2), 547-587.

Von Bertalanffy, L. (1950). An outline of general system theory. British Journal for the Philosophy of Science, 1, 114-129.

Von Foerster, H. (2003). Understanding understanding. Essays on cybernetics and cognition. New York: Springer.

Von Glasersfeld, E. (1984). An introduction to radical constructivism. In: P. Watzlawick (ed.), The invented reality (pp. 17-40). New York: Norton.

Von Uexküll, J. (1909). Umwelt und Innenwelt der Tiere. Berlin: Springer.

Von Uexküll, J. (1920). Theoretische Biologie. Berlin: Paete.

Wittgenstein, L. (1953). Philosophical Investigations (orig. Philosophische Untersuchungen). Oxford: Blackwell. 